\title{
ADVANCED CONCRETE STRUCTURES
}

\begin{abstract}
J. L. Vítek
Abstract: Concrete is a common material applied in bridge construction. The paper illustrates the development of concrete structures within last 100 years on selected examples. Although the service-life of some concrete structures is shorter than expected, the correctly designed and executed structures prove that concrete is a good material which meets the requirements. The selected structures are interesting not only as a final product, but the construction technology may be also of interest, and it is shown that the construction is a part of the design which cannot be neglected, especially in terms of the costs. Trend to minimize maintenance is leading to the design of integral bridges. Finally, a short comment on application of ultrahigh strength concrete shows that the development in concrete structure is still in progress and further improvement in the field of concrete structures can be expected.
\end{abstract}

Keywords: bridge, concrete, construction, prestressing, service life

\section{Introduction}

Concrete as a cement composite material was invented already in the $19^{\text {th }}$ century. However, its extensive development came in the $20^{\text {th }}$ century. While its first half became a domain of reinforced concrete, in its second half, prestressed structures exhibited the most significant development. Prestressing enabled not only to extend the span lengths and to make structures lighter, but also to develop advanced construction technologies. The paper will focus on outstanding structures worldwide, but also will pay attention to structures built in the Czech Republic. Finally, a relatively new material called UHPC (Ultra HighPerformance Concrete) was developed recently and provides possibility of new interesting applications.

\section{Outstanding bridges - examples}

There are many outstanding bridges worldwide. Of course, it is not possible to mention all in this short presentation. Therefore, the attention is paid to some of them which exhibit some special features. When concrete structure started to be built, a relatively poor knowledge on their behaviour and some conservatism became a reason for designing of clearly defined structural systems, preferably statically determinate. The Risorgimento bridge (built in 1911) crossing Tiber River in Rome has the span $100 \mathrm{~m}$ long (Fig. 1). The reinforced concrete structure is a beam with variable cross-section fixed into the abutments. It is a very advanced system which made it possible to design slender box girder cross-section. The structure has no bearings, which makes it very modern. The bridge is sometimes considered as an arch but it is rather a beam than an arch. The bridge is a good example of a long durability of a concrete structure, since it serves to the traffic more than 100 years without any substantial repair.

Salginatoble bridge crossing the gorge in Switzerland was designed by Robert Maillart in 1930 (Fig. 2). A typical Maillart's arch which has the span $90 \mathrm{~m}$ long is also considered as an excellent architectural monument. Although the bridge is narrow and it was designed for a vehicle of the weight $8 \mathrm{t}$, or a uniformly distributed load of $350 \mathrm{~kg} / \mathrm{m}^{2}$, it is used for local traffic, without any difficulties for almost 90 years.

Prof. Ing. Jan L. Vítek, CSc., FEng. Faculty of Civil Engineering, CTU in Prague, Thákurova 7, 16629 Prague 6 and Metrostav a.s., Prague 8,CZ, vitek@ fsv.cvut.cz 


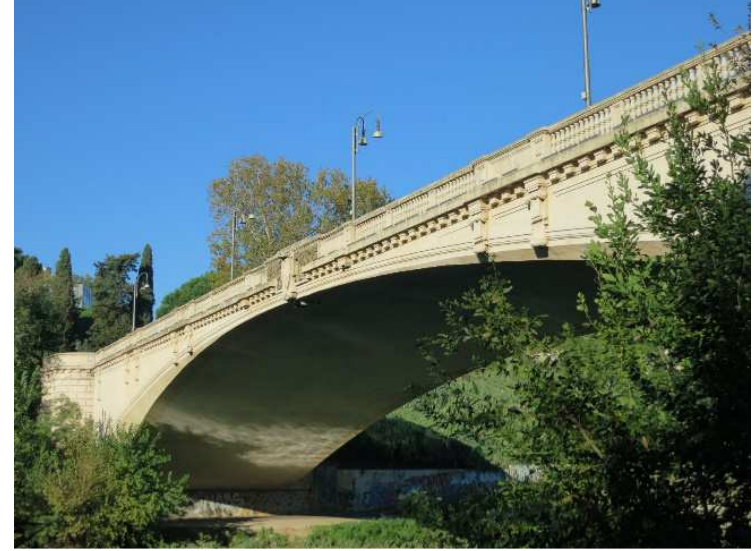

Fig. 1: Risorgimento bridge (Rome 1911)

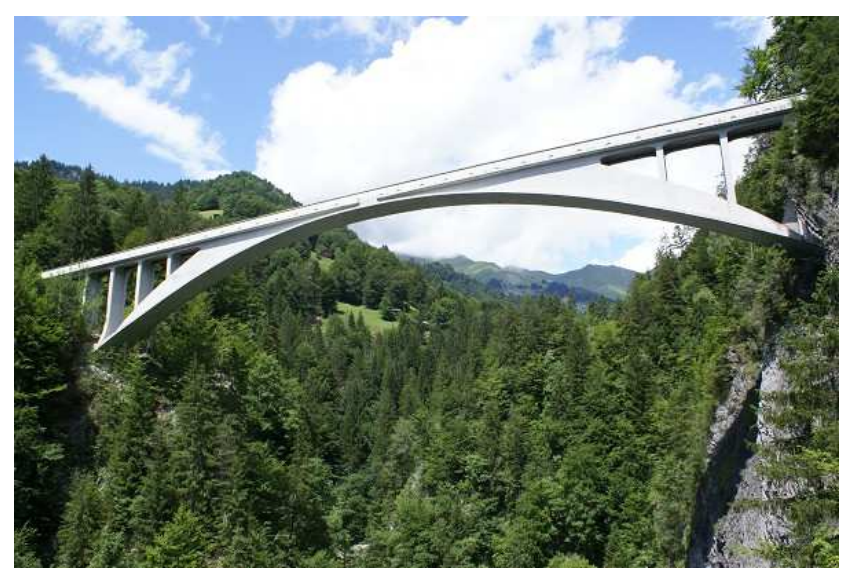

Fig. 2: Salginatobel bridge (1930)

Eugene Freyssinet is well known as a founder of prestressed concrete. But earlier, the Plougastel multispan arch bridge was built in Brittany in 1930 according to his design (Fig. 3). The bridge carries a double deck and it served for cars and trains. The each of the 3 main spans is $188 \mathrm{~m}$ long. Beside the size of the bridge the construction technology was extremely interesting especially at that time. The scaffolding for the arch span was supported on pontoons and subsequently floated to the position of individual spans. A rather simple procedure led to very efficient construction process.

Development of the motorway network required construction of tremendous amount of bridges in Germany. Kochertal bridge located on the motorway A6 between Nurnberg and Heilbronn is one of very interesting structures (Fig. 4). The bridge crosses a wide valley of a small river Kocher in the height of about $185 \mathrm{~m}$. The multi-span prestressed concrete superstructure (box girder with long cantilevers in transversal direction) has spans $140 \mathrm{~m}$ long. The overall length of the bridge is $1128 \mathrm{~m}$. The structural arrangement of the bridge is very modern also now, but the bridge was completed in 1979. The design made by F. Leonhardt was very advanced. The structure has very thin webs (in the middle of the spans only $450 \mathrm{~mm}$ ). Frame structure without bearings on high pillars also contributes to a reduced maintenance.

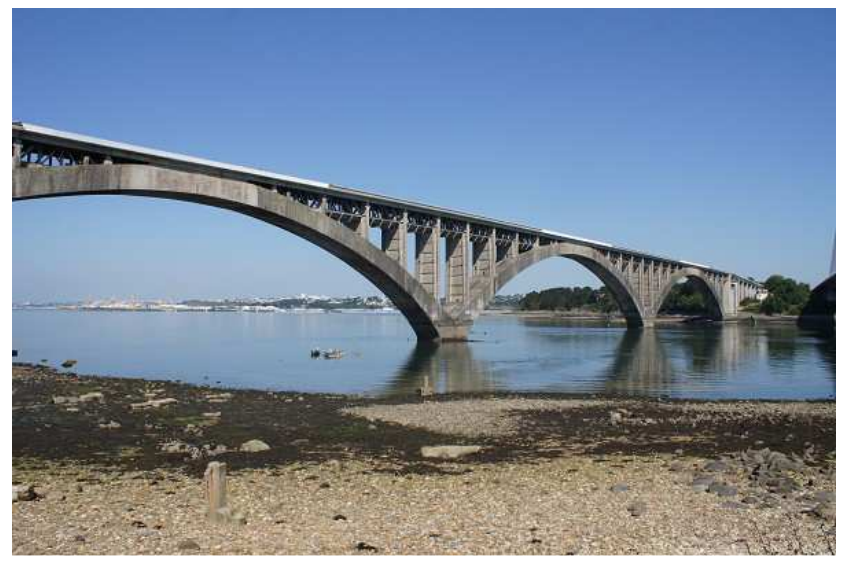

Fig. 3: Plougastel bridge (Brittany 1930)

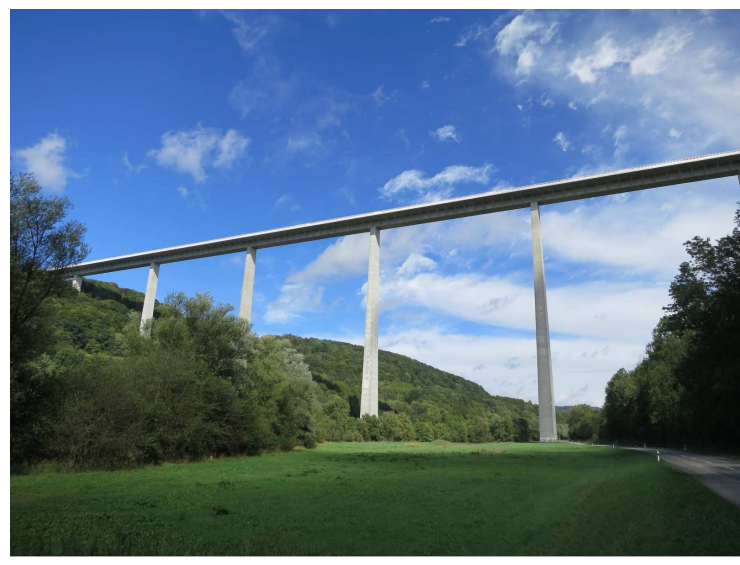

Fig. 4: Kochertal viaduct (1979)

Ch. Menn, swiss engineer, designed a lot of bridges in Switzerland. They are not of the record dimensions, but their design is very efficient and elegant. Beside the well-known Ganter bridge or many arch bridges, Sunniberg bridge (Fig. 5) close to Klosters (Switzerland) belongs to the highlights of bridge engineering (1998). A cable stayed bridge with a main span $140 \mathrm{~m}$ long has only low pylons. The bridge deck is very slender and it is prestressed by external unbonded tendons. The bridge is horizontally curved which allows for avoidance of expansion joints at its ends. It is an integral bridge. There are no bearings and no expansion joints. The structure is flexible and allows for deformation due to temperature changes without danger of excessive stresses in the structure.

Viaduct at Millau is considered as the highest bridge at least in Europe (2004). The $2.46 \mathrm{~km}$ long viaduct is a multi-span cable stayed motorway bridge (Fig. 6). The highest concrete pier is $245 \mathrm{~m}$ high, but the 
steel pylon above the steel bridge deck has the height $90 \mathrm{~m}$. The complete height of the pier including pylon is then $343 \mathrm{~m}$ above ground. The typical spans are $342 \mathrm{~m}$ long. The viaduct is exposed to severe wind load. The bridge deck is made of steel as a closed box girder. The superstructure was built by incremental launching technique. Extremely high piers would be sensitive to horizontal forces induced during the launching procedure. A special hydraulic device was developed so that the horizontal forces during launching would be completely avoided. The bridge was designed by M. Virlogeux in cooperation with the British architect N. Foster.

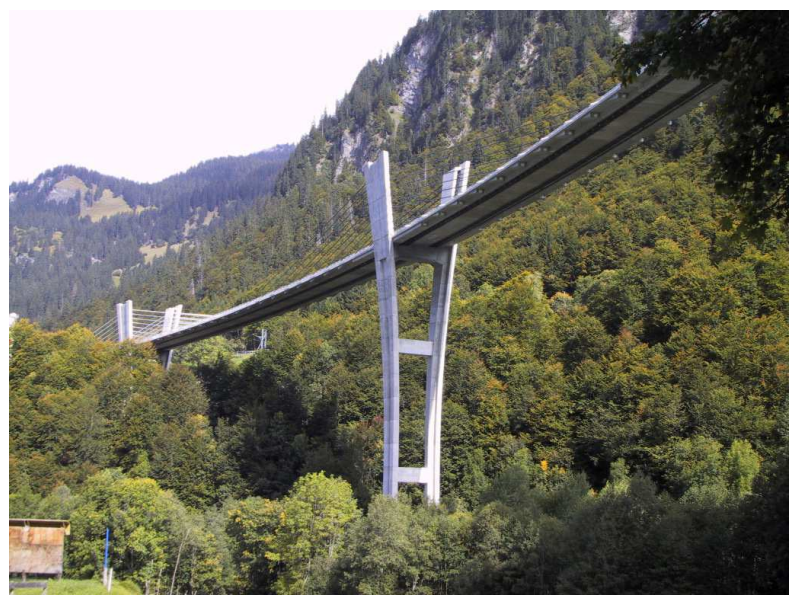

Fig. 5: Sunniberg bridge (Switzerland 1998)

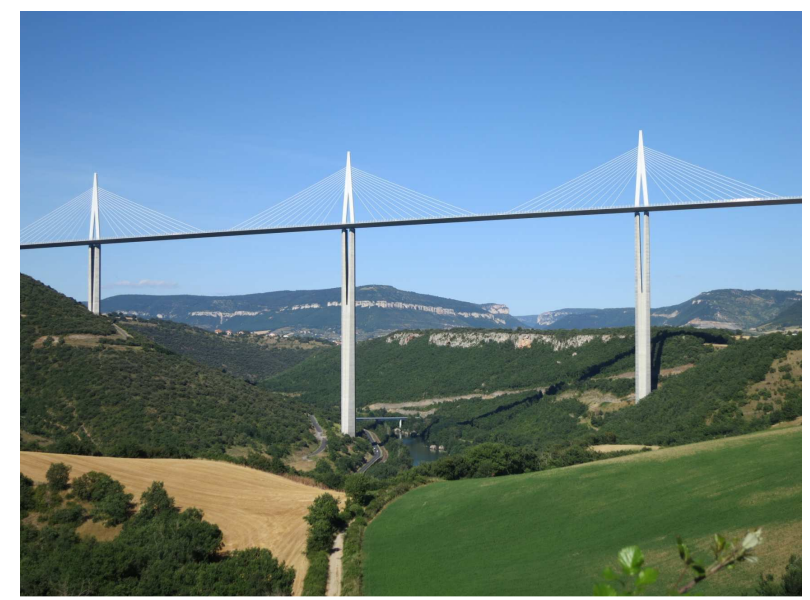

Fig. 6: Millau viaduct (2004)

At the same time (2004) the Rion-Antirion bridge (Fig. 7) was put in operation in Greece. The bridge connects the Pelopones peninsula with Greece close to the city Patras. The bridge is located in very severe conditions. The deep sea (about $60 \mathrm{~m}$ ) provides very bad conditions for foundations. The load carrying capacity of the sea bed is very small, the soil is soft. The tectonic break intersects the axis of the bridge and additionally the area is exposed to earthquake. It was necessary to design a bridge which could withstand such conditions. A cable stayed bridge was designed with three mains spans of the length 560 $\mathrm{m}$ and 2 side spans $286 \mathrm{~m}$ long. The pylons were supported on special large flat foundations of the diameter of $89.5 \mathrm{~m}$. The foundations were cast in the dry dock and then floated to the position and sunk to the sea bed. The sea bed was strengthened by a layer of gravel and by steel piles, which stiffened the subbase in shear. The pylons are stable also in the case if one span collapsed. The bridge deck is a composite steel concrete structure. If the span length changes due to the tectonic movement, or due the earthquake, the bridge will survive, since the connection of the pylons and the bridge deck allows for certain excessive movements and the stable pylons are able to take unbalanced forces in stays. M. Virlogeux participated as a consultant of the design. J. Combault was responsible for design and construction of the bridge.

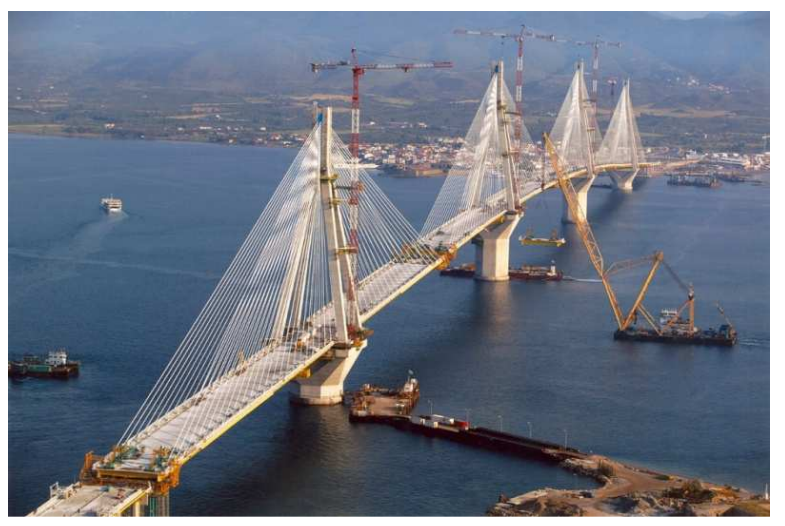

Fig. 7: Rion-Antirion bridge (Greece 2004)

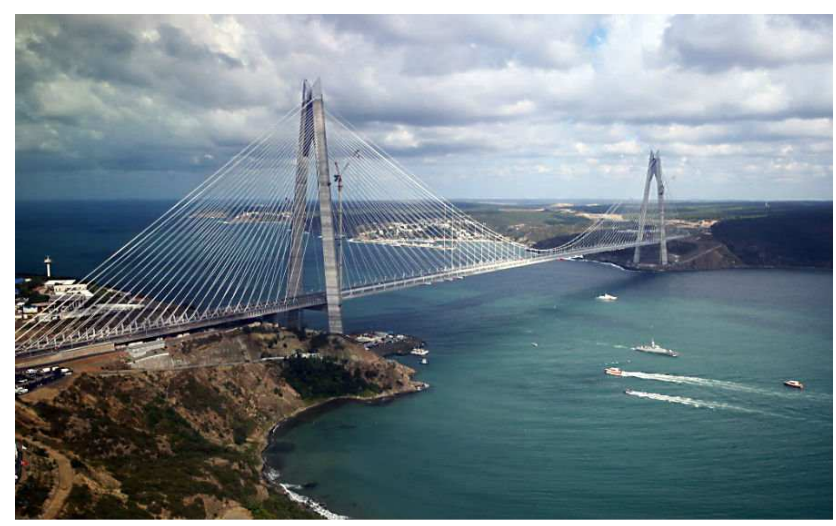

Fig. 8: $3^{\text {rd }}$ Bosphorus crossing (2016)

The $3^{\text {rd }}$ Bosphorus crossing (Fig. 8) was open to traffic in 2016. The bridge carrying 8 lane road and double track railway has a combined suspension and cable stayed system. The main span is $1408 \mathrm{~m}$ long. The pylons are $330 \mathrm{~m}$ high. The bridge deck is $59 \mathrm{~m}$ wide. The bridge was designed by M. Virlogeux and J. F. Klein. Very strict requirements on deformations of the bridge are necessary because of the railway traffic. A wind load is rather severe in the location. The hangers from suspension cables are anchored into 
the bridge deck between the railway and the road, while the stays are anchored at the edges of the crosssections. The central part of the span is supported only on suspension cables, while the parts closer to supports are supported only by stays. This arrangement is favourable for the stability of the entire structure.

\section{Integral bridges}

The costs of the bridge are composed of the investment (initial) costs and costs for maintenance, repairs, etc. Contemporary design philosophy tends to reduce the maintenance costs, since they are also associated with the necessity to close the bridge or at least to limit its operation for a certain period. At the bridge, there are parts which have shorter service life than the structure itself. They have to be replaced several times during the service life of the bridge. Some of them are exposed to heavy load and are sensitive to damage. Therefore, there is a trend to eliminate these parts if possible. The expansion joints and bearings are rather expensive parts which may be in a suitable design avoided. The expansion joints allow for an extension of the bridge mainly due to temperature changes. If they should be eliminated the structure cannot be too long. The bridge which is completely without expansion joints and bearings is called and integral bridge. The bridges where bearings and expansion joints are eliminated only on a part of the length are called semi-integral bridges. Design of integral bridges requires more detailed analysis, since the changes in length of the bridge deck due to temperature have to be transferred by flexibility of piers and foundations. Special arrangement at the ends of integral bridges at the ends have to be designed, so that the expansion joints could be removed and the vehicles could fluently go from the bridge to the ordinary road. The shorter bridges up to approximately $50 \mathrm{~m}$, may be designed as integral structures, longer bridges are usually semi-integral structures. As an example, the Scherkondetal viaduct (Fig. 9) has a typical span $44 \mathrm{~m}$ long, but its length is $576,5 \mathrm{~m}$ without any joint.

\section{Reduction of the self-weight of the structures}

When increasing the span of the bridge, the dead load (self-weight in particular) becomes the highest load on the bridge. It is a natural trend to reduce the self-weight, which would allow to design longer spans or to increase the load carrying capacity. The long span bridges usually designed as box girders. The flanges are necessary for carrying the load and for transfer of compression or tension. The webs carry the shear forces and keep the shape of the cross-section. If the thickness of webs is reduced, substantial savings of the weight may be achieved. There were attempts to replace concrete webs by corrugated steel webs. The initial idea came from France, but most of the bridges were built in Japan. The system is rather labour consuming. The other idea invented in Japan is using high strength concrete prestressed precast elements for webs. Their thickness may be then significantly reduced. The elements are prestressed in the direction of the principle tensile stress, while in the other direction of the principle compression stress, the compression force is carried by high strength concrete. If the construction process is suitably designed, substantial savings may be expected. The system was used in the segmental construction of several viaducts in Japan. An example of a $3 \mathrm{~km}$ long viaduct is plotted in Fig. 10.

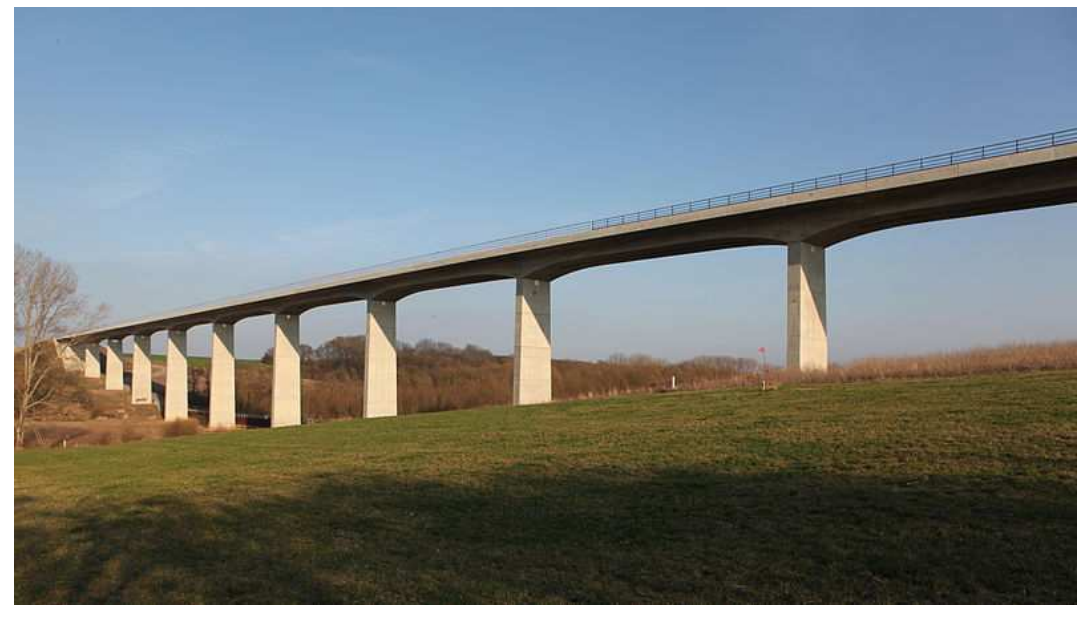

Fig. 9: Scherkondetal viaduct (Germany 2011)

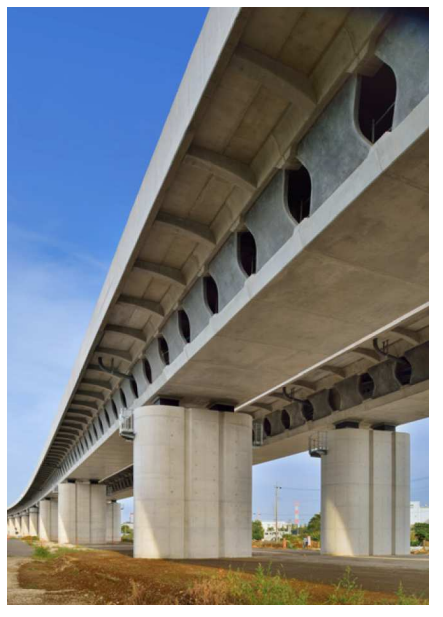

Fig. 10: Okegawa viaduct (Japan 2014) 


\section{Two examples of advanced structures built in the Czech Republic}

The bridge over Rybny Creek is located on the motorway D8 connecting Prague and Dresden. The bridge is a continuous beam with 7 spans (58 m the longest). The original design assumed to build two bridge structures, each for one direction of the traffic. It was necessary to shorten the construction time, only one structure was designed with a wide cross-section (about $30 \mathrm{~m}$ ). The cross-section is made as a box girder with long cantilevers supported by precast concrete struts. Such section is very efficient and nowadays very often designed, although it was used already e.g. at the Kochertal viaduct in $70^{\text {th }}$ of the last century. The bridge was built using an incremental launching method, which appeared very effective, although the weight of the entire superstructure was about $20000 \mathrm{t}$.

The prestressed concrete tanks for storage of oil or petrol, may serve as a good example of concrete structure with long service life. The four tanks were built at Loukov in Moravia. Each tank has a content of $35000 \mathrm{~m}^{3}$. The tanks are of a cylindrical shape, the internal diameter is about $47.8 \mathrm{~m}$, the height of the wall only $600 \mathrm{~mm}$ thick is $21.4 \mathrm{~m}$. The roof is a circular shell $250 \mathrm{~mm}$ thick. The structure is made completely of prestressed concrete. The foundation slab is prestressed in two directions, as well as the walls. The horizontal prestressing units are anchored in four vertical ribs located on the outer surface of the cylindrical wall. Vertical prestressing units connect the foundation slab and the walls and they are anchored on the top of the wall. The roof was cast inside the tank and then lifted to the final position using suspension on steel bars. The entire structure is watertight. The safety against any leakage is very important, therefore a laminate two-layer system is glued on the walls inside. If any leakage of the first layer was observed, the alarm is activated, the tank must be emptied and the sealing system repaired. The service-life is designed for more than 50 years, while usual steel tanks have a service-life about $25-30$ years. The tanks were from technological reasons covered by the earth. The structure was finished in 2011.

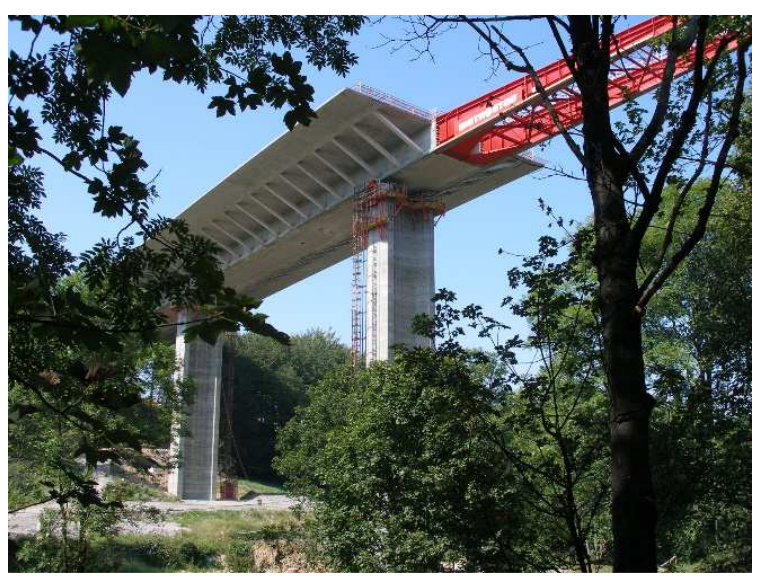

Fig. 11: Bridge over Rybny Creek (Czech Republic 2006)

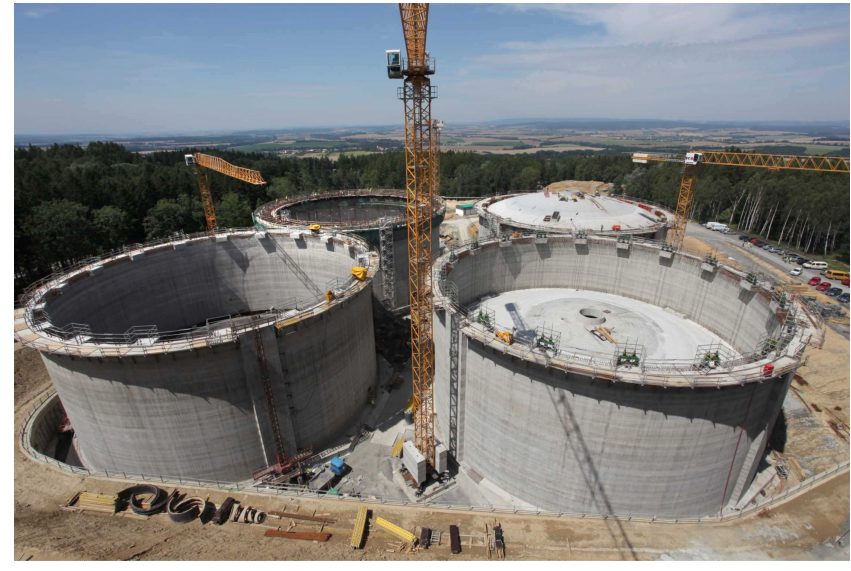

Fig. 12: Prestressed oil tanks (Czech Republic 2011)

\section{UHPC and its applications}

UHPC (Ultra-High-Performance Concrete) started to be developed in $90^{\text {th }}$ of the last century, when the chemical admixtures were progressively improved. If a high strength of concrete should be achieved, the water contents needs to be minimized and the density of the material must be the highest possible. The reduction of the water content was not possible without efficient superplasticizers. The avoidance of pores in the concrete structure needs addition of fine materials like microsilica, and stone powders. Finally, it was possible to produce a material with the strength exceeding $150 \mathrm{MPa}$ in compression. In order to avoid brittle failure, the material is reinforced by small fibres from high strength steel. The tensile strength exceeds $10 \mathrm{MPa}$. The character of a concrete type material is promising mainly in structures which are prestressed. However, the excellent mechanical properties also guarantee an outstanding durability of elements made of the UHPC, since the density of the material does not allow for penetration of water into the structure.

The first footbridge made of UHPC was built in Canada in 1997 (Sherbrook footbridge). Since that time, the material was used for footbridges, bridges, roofs and for architectural elements used preferably in facades. The excellent durability should guarantee a long service life without the need of replacement. 
Recently, applications for rehabilitation and strengthening of existing structures become more often. The material is still considered as new and the experience is rather limited. The design guides are slowly developed. The most of applications in bridges are now in Malaysia, where the experience is appreciated, and the detailed design rules are not so strictly required by the local authorities. About 100 bridges were already built there, while only one, e.g. in Germany. The city road bridge built in Montpelllier is shown in Fig. 13.

In the Czech Republic, we had a chance to build a long cable stayed footbridge in Čelákovice crossing the Labe River (Fig. 14). The cable stayed footbridge has a main span $156 \mathrm{~m}$ long and two side spans $43 \mathrm{~m}$ long. The bridge deck is made of segments made of UHPC. The structure is prestressed and the design service-life of the bridge deck is 120 years.

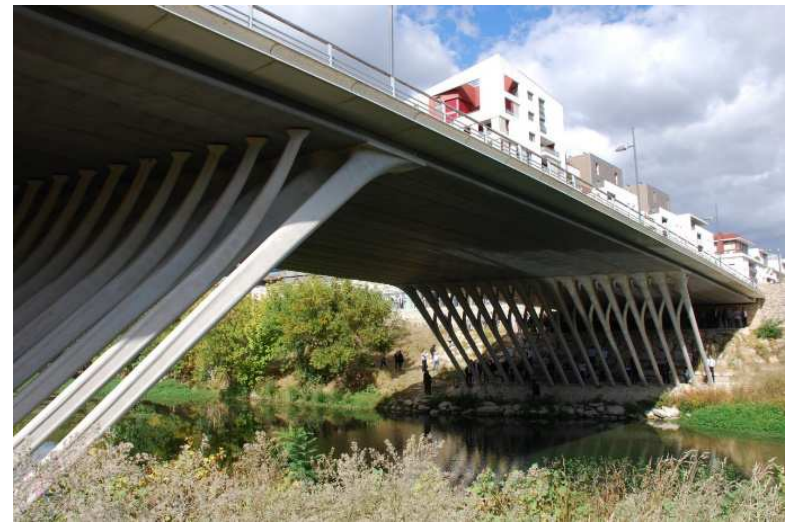

Fig. 13: Road bridge in Montpellier (France 2014)

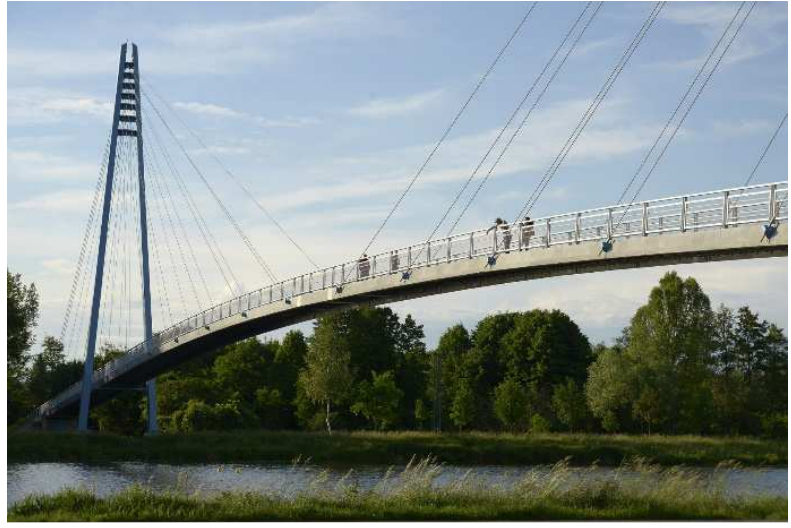

Fig. 14: Footbridge in Čelákovice (Czech Republic 2014)

\section{Conclusions}

The paper illustrates some outstanding structures built in the world, but also shows that interesting structures may be built in our small country. The concrete structures may suffer from some difficulties as we see in our daily life, but usually the problem is not in concrete itself, but in the incorrect design or execution. The increasing experience, improving materials and more detailed production control are promising and concrete structures hopefully will be developed also in the future and will be successfully and reliably serve to its purpose.

\section{Acknowledgement}

Some data used in this paper resulted from the research supported by the Technological agency (Project no. TE 01020168) and by the Ministry of industry and trade (Project no. FV20472). The supports are gratefully acknowledged.

\section{References}

Homma, A., Kojima, T., Kasuga, A., Nakatsumi, K. (2015) Design and construction of Okegawa viaduct which has precast segmental U-shaped butterfly web girders. Proc. of the fib Symposium "Concrete - Innovation and Design”, Copenhagen May 18-20, 2015

Kalny, M., Kvasnicka, V., Komanec, J, Broz, R., Koukolik, P., Vitek, J.L. (2015) Cable stayed footbridge with UHPC deck over the Labe River in Celakovice. Proc. of the fib Symposium "Concrete - Innovation and Design", Copenhagen May 18-20, 2015

Ricciotti, R., Pastor, F., Hajar, Z., Bernardi, S. (2017) La Republique Bridge in Montpellier. RILEM Proc. PRO 106 of AGFC-ACI-fib-RILEM Int. Symposium on Ultra-High Performance Concrete, UHFRC 2017 - Oct. 2-4, 2017, Montpellier, France, pp.727-736

Svensson, H. (2011) Schrägkabelbrücken 40 Jahre Erfahrung weltweit. Ernst \& Sohn, Berlin, Germany

Troyano, L. F. (2003) Bridge Engineering a Global Perspective. Telford, London, UK

Vítek, J.L., Stráský, J., Brož, R. (2006) Bridge over the Rybny Creek. Proc. of the $2^{\text {nd }}$ fib Congress, June 5-8, Naples, Italy, Session 2, Vol. I, pp. 72-73

Vítek, J.L., Zich, M. (2010) Construction and Monitoring of Prestressed Concrete Tanks. Betontag 2010, Wien, Tagungsband, OVBB, Wien, 190-193 